\title{
Diode Laser Welding/Brazing of Aluminum Alloy to Steel Using a Nickel Coating
}

\author{
Jin Yang ${ }^{1,2} \mathbb{1}^{\mathbb{D}}$, Jieshi Chen ${ }^{1,2}$, Wanqin Zhao ${ }^{1,2}$, Peilei Zhang ${ }^{1,2}$, Zhishui $\mathrm{Yu}^{1,2, *}$, Yulong $\mathrm{Li}^{3, *}$, \\ Zhi Zeng ${ }^{4}$ and Norman Zhou ${ }^{5}$ \\ 1 School of Materials Engineering, Shanghai University of Engineering Science, Shanghai 201620, China; \\ jyang@sues.edu.cn (J.Y.); cjshbb@163.com (J.C.); linazhaolinazhao@foxmail.com (W.Z.); oxidpl@126.com (P.Z.) \\ 2 Shanghai Collaborative Innovation Center of Laser Advanced Manufacturing Technology, \\ Shanghai 201620, China \\ 3 Key Laboratory of Robot and Welding Automation of Jiangxi Province, School of Mechanical and Electrical \\ Engineering, Nanchang University, Nanchang 330031, China \\ 4 School of Mechanical, Electronic, and Industrial Engineering, University of Electronic Science and \\ Technology of China, Chengdu 611731, China; zhizeng@uestc.edu.cn \\ 5 Center for Advanced Materials Joining, University of Waterloo, Waterloo, ON N2L 3G1, Canada; \\ nzhou@uwaterloo.ca \\ * Correspondence: yu_zhishui@163.com (Z.Y.); liyulong1112ster@gmail.com (Y.L.)
}

Received: 18 May 2018; Accepted: 30 May 2018; Published: 4 June 2018

\begin{abstract}
Joining $\mathrm{Al}$ alloy to steel is of great interest for application in the automotive industry. Although a vast number of studies have been conducted to join $\mathrm{Al}$ to steel, the joining of $\mathrm{Al}$ to steel is still challenging due to the formation of brittle Fe-Al intermetallic compounds. In this work, the microstructure and mechanical properties of the dissimilar $\mathrm{Al} /$ steel joints with and without a nickel coating are comparatively investigated. A homogenous reaction layer composed of $\mathrm{FeZn}_{10}$ and $\mathrm{Fe}_{2} \mathrm{Al}_{5}$ is formed at the interface in the joints without $\mathrm{Ni}$ coating, and the joint facture load is only $743 \mathrm{~N}$. To prevent the formation of brittle $\mathrm{Fe}_{2} \mathrm{Al}_{5}$, Ni electroplated coating is applied onto a steel surface. It has been shown that a nonhomogeneous reaction layer is observed at the interfacial region: $\mathrm{Ni}_{5} \mathrm{Zn}_{21}$ is formed at the direct irradiation zone, while $\mathrm{Al}_{3} \mathrm{Ni}$ is formed at the fusion zone root. The microhardness of the interfacial layer is reduced, which leads to the improvement of the joint mechanical properties. The average fracture load of the $\mathrm{Al} / \mathrm{Ni}$-coated steel joints reaches $930 \mathrm{~N}$. In all of the cases, failure occurs at the Ni coating/fusion zone interface.
\end{abstract}

Keywords: laser welding/brazing; aluminum alloy; Ni coating; interfacial microstructure; intermetallic compounds; mechanical properties

\section{Introduction}

The joining of dissimilar materials offers the potential to utilize the advantages of different materials, often providing a whole structure with unique mechanical properties. Aluminum alloys can reduce the weight of structural parts due to its light weight, and steel has a high strength. Hybrid structures of aluminum alloy and steel are suggested in automotive applications to improve the fuel efficiency and control air pollution through reducing the weight [1-3].

The joining of aluminum alloys to steel is a great challenge due to the large differences in the thermophysical properties between these two materials, and especially the formation of inherently hard and brittle $\mathrm{Fe}-\mathrm{Al}$ intermetallic compounds (IMCs) at elevated temperatures, such as $\mathrm{FeAl}$, $\mathrm{FeAl}_{2}, \mathrm{FeAl}_{3}$, and $\mathrm{Fe}_{2} \mathrm{Al}_{5}$. Early attempts at fusion welding of steel to aluminum alloys suffered from joint brittleness at the dissimilar interface caused by extensive IMC formation. More recently, 
many advanced welding technologies have been applied in $\mathrm{Al} /$ steel joining, such as friction stir welding [4], ultrasonic welding [5], explosive welding [6], laser keyhole welding [7], as well as arc, laser, and laser-hybrid welding/brazing [8-12]. The welding/brazing offers a great potential for $\mathrm{Al} /$ steel joining, owing to the advantage in reducing residual stress and controlling the IMCs. In the welding/brazing of $\mathrm{Al}$ to steel, the workpieces and filler metal are heated or melted by a heat source, and the joint has dual-characteristics, i.e., it has a fusion-welded joint at the Al side, and a brazed joint at the steel side. Some related investigations have claimed the observation of $\mathrm{Fe}-\mathrm{Al}$ IMCs in $\mathrm{Al} /$ steel joints by welding/brazing [9-11].

The use of materials (interlayer, filler metal, coating, or their combinations) that becomes part of the joint has proven to be sufficient to inhibit the formation of brittle IMCs in dissimilar materials welding/brazing, such as $\mathrm{Mg} / \mathrm{Ti}$ [13], $\mathrm{Al} / \mathrm{Mg}$ [14,15], and NiTi/Ti6Al4V [16]. For example, in the investigation of laser joining of NiTi to Ti6Al4V, Oliveira et al. [16] successfully inhibited the formation of brittle Ni-Ti IMCs by inserting a niobium interlayer. The common features of the materials can be summarized as: (1) a higher melting point than parent metals, so that the alloy mixing of parent materials can be deterred; (2) excellent metallurgical capability with parent metals; (3) no brittle or much less brittle reaction products are formed with either parent material. With these criteria in mind, $\mathrm{Ni}$ is considered as a promising candidate for the dissimilar $\mathrm{Al} /$ steel joining, because of its good miscibility with Fe and sound metallurgical capability with Al. Although its melting point is $83^{\circ} \mathrm{C}$ lower than $\mathrm{Fe}$, the inhibition of alloy mixing by Ni still can be accomplished by using accurately tailored energy distribution during welding. In fact, Chen et al. $[17,18]$ made attempts to join $\mathrm{Al}$ to steel with a Ni interlayer. However, brittle Fe-Al IMCs were still formed by the direct mixing of Fe and $\mathrm{Al}$, owing to completely melting the $\mathrm{Ni}$ interlayer by Nd:YAG laser penetration welding technology.

In the present study, a diode laser with a more uniform energy distribution is applied. Compared to the keyhole mode in the Nd:YAG laser penetration welding, a conduction mode is figureachieved, which eases the accurate control of energy distribution and thus enables the welding/brazing technology. $\mathrm{Ni}$, in the form of electroplated coating on steel, is used in a lap joint configuration. To highlight the effect of Ni coating, the microstructure and mechanical properties of laser $\mathrm{Al} / \mathrm{Ni}$-coated steel joint is drawn as a comparison with that of the laser $\mathrm{Al} /$ bare steel joint.

\section{Experimental Procedure}

In this study, 1.5-mm thick 5754 aluminum alloy and DP980 steel sheets were used as the base materials. Their chemical compositions and mechanical properties are given in Tables 1 and 2 . A 1.6-mm diameter $\mathrm{Zn}$-based filler metal ( $\mathrm{Zn}$-22Al) filler metal with solidus and liquidus temperatures of $441^{\circ} \mathrm{C}$ and $482{ }^{\circ} \mathrm{C}$ was used. An anticorrosive brazing flux Superior No. 20 was used.

Table 1. Chemical composition of the materials in wt.\%.

\begin{tabular}{ccccccccccccc}
\hline Materials & Mg & Cr & Mn & Si & $\mathbf{C u}$ & Zn & Ti & Fe & Mo & C & Al & B \\
\hline DP 980 steel & - & 0.15 & 2.1 & 0.05 & - & - & - & Bal. & 0.35 & 0.135 & 0.45 & 0.007 \\
Al 5754 & $2.6-3.6$ & 0.3 & 0.5 & 0.4 & 0.1 & 0.2 & 0.15 & 0.4 & - & - & Bal. & - \\
Zn-22Al & - & - & - & - & $<0.003$ & Bal. & - & $<0.02$ & - & - & 22 & - \\
\hline
\end{tabular}

Table 2. Mechanical properties of the base materials.

\begin{tabular}{cccc}
\hline Materials & Yield Strength (MPa) & Ultimate Strength (MPa) & Elongation (\%) \\
\hline DP980 steel & $666 \pm 36$ & $1005 \pm 7$ & $12.5 \pm 0.7$ \\
Al 5754 & $85 \pm 11$ & $239 \pm 3$ & $16.2 \pm 1.3$ \\
\hline
\end{tabular}

Base materials were machined as rectangular strips of $50 \times 60 \mathrm{~mm}^{2}$. The aluminum alloy sheets went through a very strict two-step cleaning process, which was shown in our previous study [19]. The steel sheets were cleaned in acetone, and then ground to 1000 grit using SiC abrasive 
paper and again ultrasonically cleaned in acetone. The prepared surfaces were then immediately electroplated with electrolytic pure $\mathrm{Ni}$. In the $\mathrm{Ni}$ electroplating process, the clean steel sample was the cathode, and the pure $\mathrm{Ni}$ sheet was the anode. The composition of the electroplating solution and the electroplating conditions are listed in Table 3. Figure 1a shows a schematic of the Ni electrodeposition process. To get a uniform $45-\mu \mathrm{m}$ thick Ni layer on the steel, different cathode current densities and plating times were tested. The electrodeposition of $\mathrm{Ni}$ using a cathode current density of $300 \mathrm{~mA} / \mathrm{cm}^{2}$ for $20 \mathrm{~min}$ was found to provide a $45 \pm 3$ - $\mu \mathrm{m}$-thick pure Ni coating layer on the steel with a defect-free interface. Figure $1 \mathrm{~b}$ shows the SEM images of Ni-coated steel. Energy-dispersive $\mathrm{X}$-ray spectrometer (EDS) analysis of the electrodeposited layer on the steel showed a pure Ni coating.

Table 3. Composition of Ni electroplating solution and electroplating parameters.

\begin{tabular}{cccc}
\hline \multicolumn{2}{c}{ Plating Solution Composition (g/L) } & \multicolumn{2}{c}{ Electrodeposition Parameters } \\
\hline $\mathrm{NiSO}_{4} \cdot 6 \mathrm{H}_{2} \mathrm{O}$ & 180 & Cathode current density & $300 \mathrm{~mA} / \mathrm{mm}^{2}$ \\
$\mathrm{NH}_{4} \mathrm{Cl}$ & 25 & Temperature & $43-60{ }^{\circ} \mathrm{C}$ \\
$\mathrm{H}_{3} \mathrm{BO}_{3}$ & 30 & $\mathrm{pH}$ & $5.6-5.9$ \\
& & Time & $10-25 \mathrm{~min}$ \\
\hline
\end{tabular}

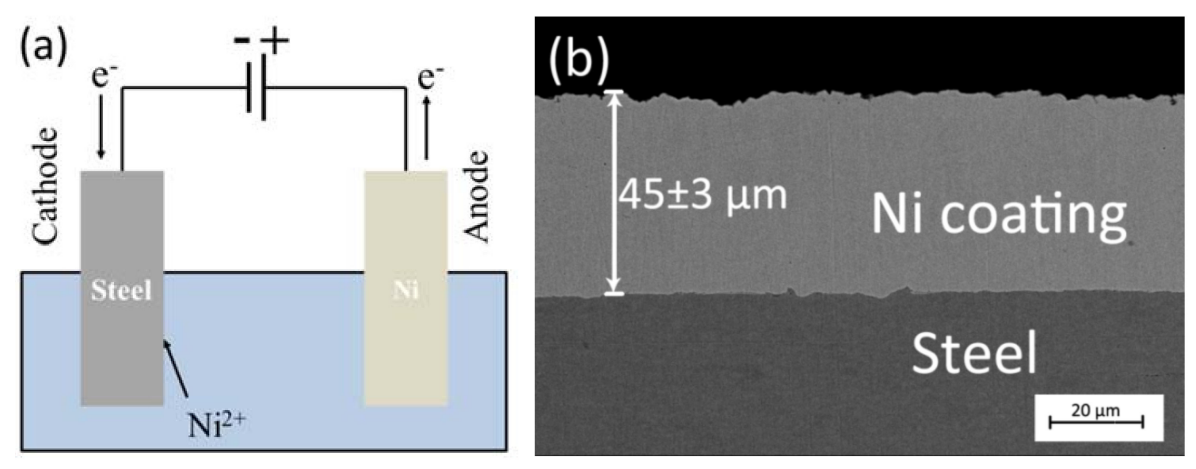

Figure 1. (a) Schematic of the Ni electrodeposition process on steel; (b) cross-section of the Ni electrodeposited layer on the steel substrate.

An integrated Panasonic six-axis robot and a 4-kW Nuvonyx diode laser system were used for laser welding/brazing. A $1 \times 12 \mathrm{~mm}^{2}$ rectangular laser beam intensity profile was obtained at the focal point. The filler metal was placed on the surface of the steel sheet. Shielding gas $(99.99 \% \mathrm{Ar})$ was applied with a flow rate of $15 \mathrm{~L} / \mathrm{min}$ to limit oxidation. The experimental setup of the laser welding/brazing is shown in Figure 2a. Before the experiment, preliminary trials were conducted to obtain a visually acceptable joint. The process parameters are listed in Table 4.

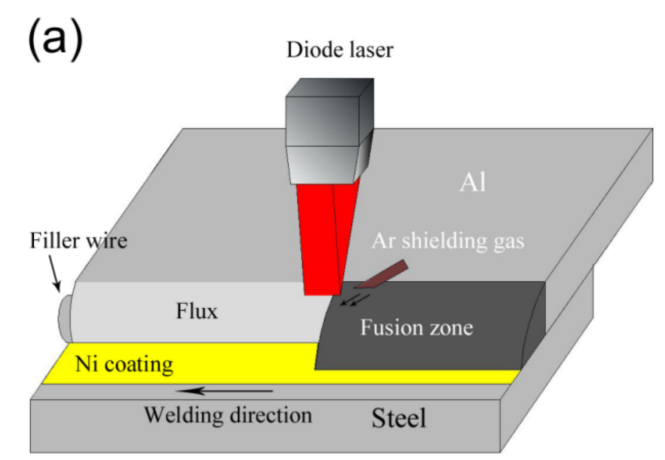

(b)

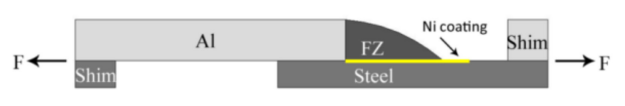

Figure 2. (a) Schematic description of the laser welding/brazing layout used for joining the aluminum alloy to Ni-coated steel sheets in the lap joint configuration and (b) schematic illustration of the tensile-shear test samples. 
Table 4. Experimental parameters used in the laser welding/brazing.

\begin{tabular}{cc}
\hline Welding Parameters & Value \\
\hline Laser power $(\mathrm{kW})$ & 2.6 \\
Defocusing amount $(\mathrm{mm})$ & 3 \\
Welding speed $(\mathrm{m} / \mathrm{min})$ & 0.5 \\
Flow rate of shielding gas $\mathrm{Ar}(\mathrm{L} / \mathrm{min})$ & 15 \\
\hline
\end{tabular}

After welding, tensile test specimens with the dimensions of $5 \times 90 \mathrm{~mm}^{2}$ were cut from the assemblies by the abrasive water jet technique. The specimens were evaluated by tensile-shear tests at room temperature with a crosshead speed of $1 \mathrm{~mm} / \mathrm{min}$. Shims were clamped to each end of the specimens to keep the joint interface parallel to the loading direction, as shown in Figure 2b. The joint strength was presented as a fracture load with the unit of newton $(\mathrm{N})$, as the geometries of the tensile samples were not identical, because of various fusion zone (FZ) geometries and complex stresses. The microhardness testing was carried out with a 100-g load force and 15-s dwell time.

The specimens were cut across the joints to obtain cross-sections to study the macrostructure and microstructure. The specimens were then mechanically ground using 400, 600, 800, 1000, and 1200 grades of $\mathrm{SiC}$ papers followed by polishing with a 1- $\mu \mathrm{m}$ diamond suspension. Keller's reagent was used to reveal the microstructure of the sectioned joints. They were then observed using an Olympus BX51M optical microscope (OM). The microstructure and fracture morphology were analyzed using a JEOL JSM 6460 scanning electron microscope (SEM). The composition was determined using Oxford INCA energy-dispersive $X$-ray spectrometer (EDS). The phase constitution of fractured joints was analyzed by $\mathrm{X}$-ray diffraction (XRD) using a diffractometer with $\mathrm{Cu}$ Ka1 radiation.

\section{Results}

\subsection{Microstructures}

The top surface appearance and typical cross-section of the laser $\mathrm{Al} / \mathrm{Ni}$-coated steel joint are presented in Figure 3. With a 3-mm defocusing amount above the filler metal, a uniform FZ with good wetting (wetting angle $53.5^{\circ}$ ) on Ni coating substrate was observed. As marked in Figure $3 b$, the FZ/Ni coating interface was mainly divided into two zones: direct irradiation zone and the FZ root. The microstructure was observed to vary from the direct irradiation zone to the FZ root. The local heating characteristics of the temperature gradient along the interface were considered as the main reason for the evident variation of microstructure along the FZ/Ni interface $[20,21]$.
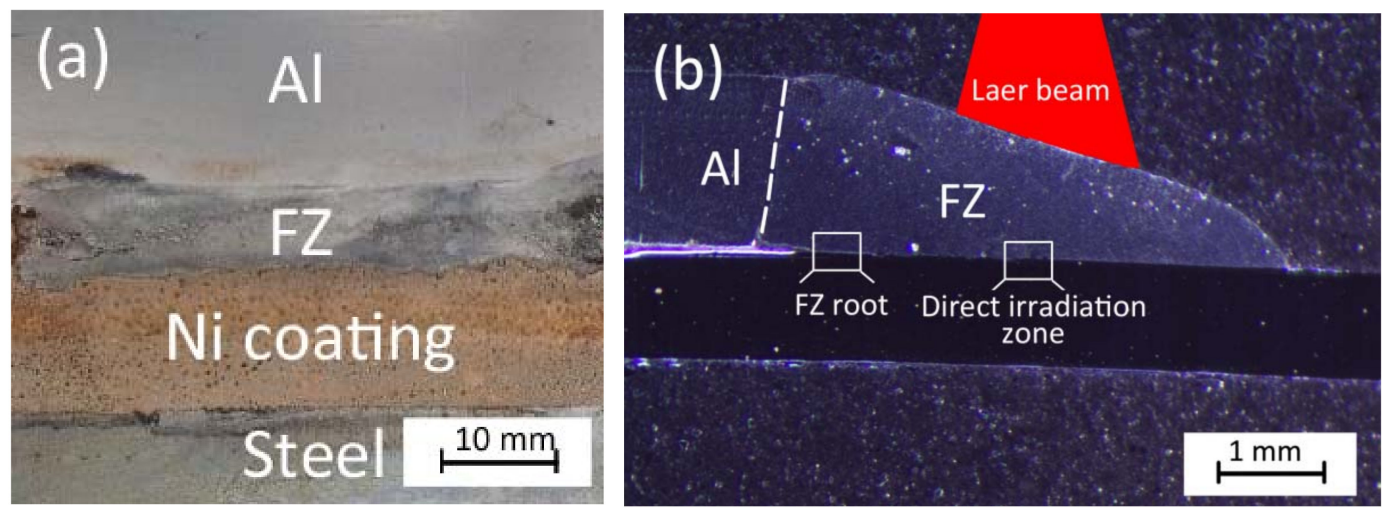

Figure 3. Laser Al/Ni-coated steel joint: (a) top surface appearance and (b) cross-section.

Figure 4 displays the backscattered electron image (BEI) of the interfacial area in the $\mathrm{Al} / \mathrm{Ni}$-coated steel joint. The Ni coating was clearly observed at the interface, indicating that only part of the Ni 
coating was dissolved into the FZ during laser irradiation. A nonhomogeneous reaction layer was formed at the interface. In the direct irradiation zone, a wavy light layer with a thickness of $3.5 \mu \mathrm{m}$ was observed (Figure 4a,c). To analyze this reaction layer, EDS point analysis was performed at point 1 . According to Al-Ni-Zn ternary phase diagram [22,23], the possible phase of the reaction layer was $\mathrm{Ni}_{5} \mathrm{Zn}_{21}$, since it consisted of $6.1 \pm 0.7$ at.\% Al, $74.4 \pm 0.3$ at.\% $\mathrm{Zn}$, and $19.4 \pm 0.5$ at. $\%$ Ni (Table 5). This phase was then confirmed by $\mathrm{XRD}$, which will be shown later. Between $\mathrm{Ni}_{5} \mathrm{Zn}_{21}$ and $\mathrm{FZ}$, a large number of dark particles was obvious. The EDS results shows that they had the average chemical composition of $68.9 \pm 0.9$ at. $\% \mathrm{Al}, 3.5 \pm 0.3$ at. $\% \mathrm{Zn}$, and $27.6 \pm 0.4$ at. $\% \mathrm{Ni}$, which corresponded to the possible phase of $\mathrm{Al}_{3} \mathrm{Ni}$. In the $\mathrm{FZ}$ root, a 1.5- $\mu \mathrm{m}$ thick uniform dark layer was formed at the $\mathrm{FZ} / \mathrm{Ni}$ interface (Figure $4 \mathrm{~b}, \mathrm{~d}$ ). Base on EDS analysis, it had the average composition of $69.5 \pm 5.1$ at.\% Al, $7.2 \pm 0.9$ at. $\% \mathrm{Zn}$, and $23.2 \pm 4.5$ at. $\% \mathrm{Ni}$, which was identified as $\mathrm{Al}_{3} \mathrm{Ni}$.

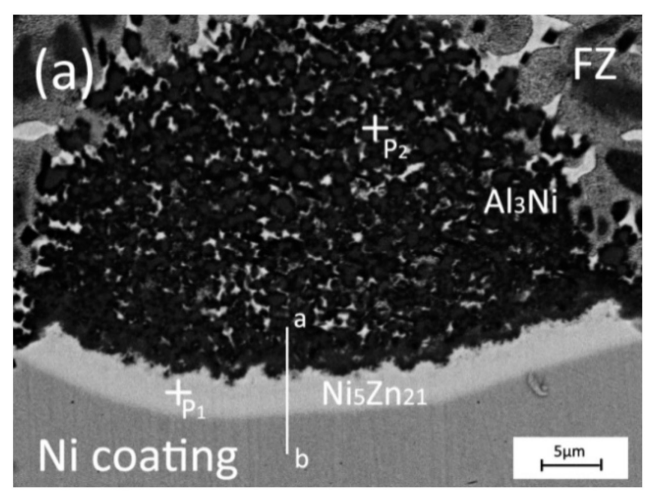

(c)

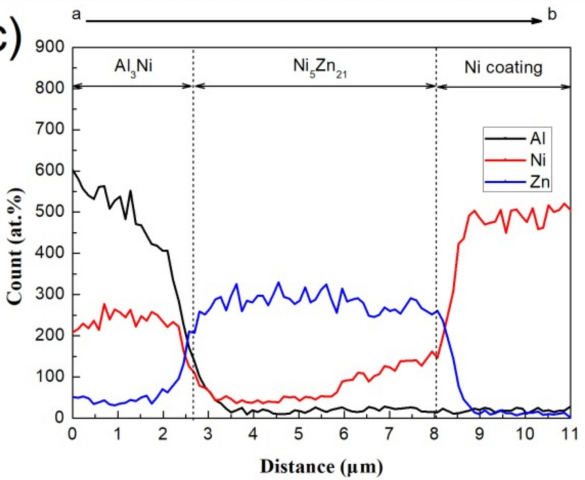

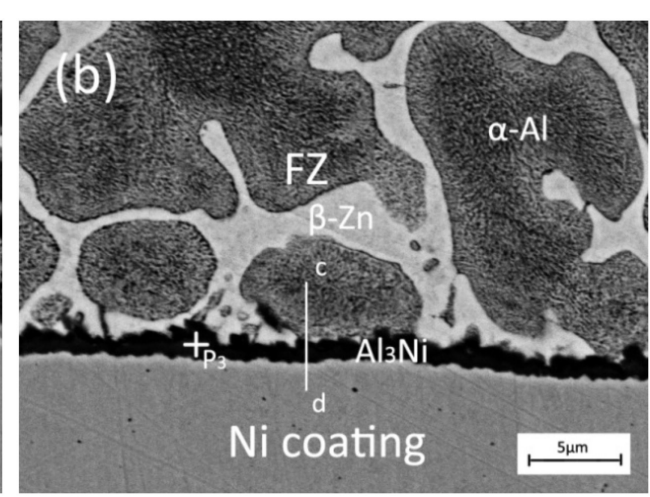

(d)

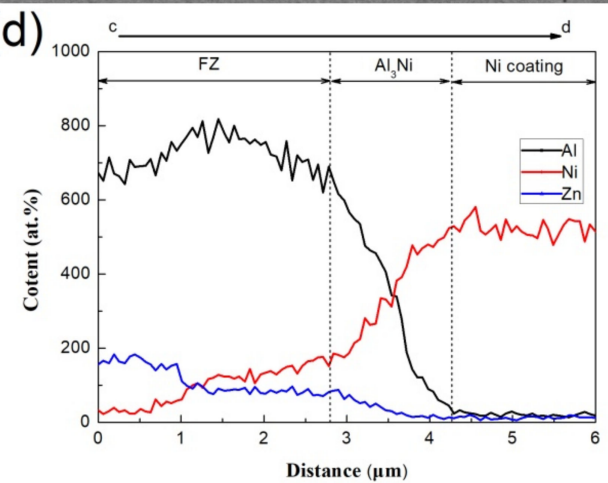

Figure 4. Backscattered electron image (BEI) images and energy-dispersive X-ray spectrometer (EDS) line scanning of the laser $\mathrm{Al} / \mathrm{Ni}$-coated steel joint at different zones: $(\mathbf{a}, \mathbf{c})$ direct irradiation zone; $(\mathbf{b}, \mathbf{d})$ fusion zone (FZ) root.
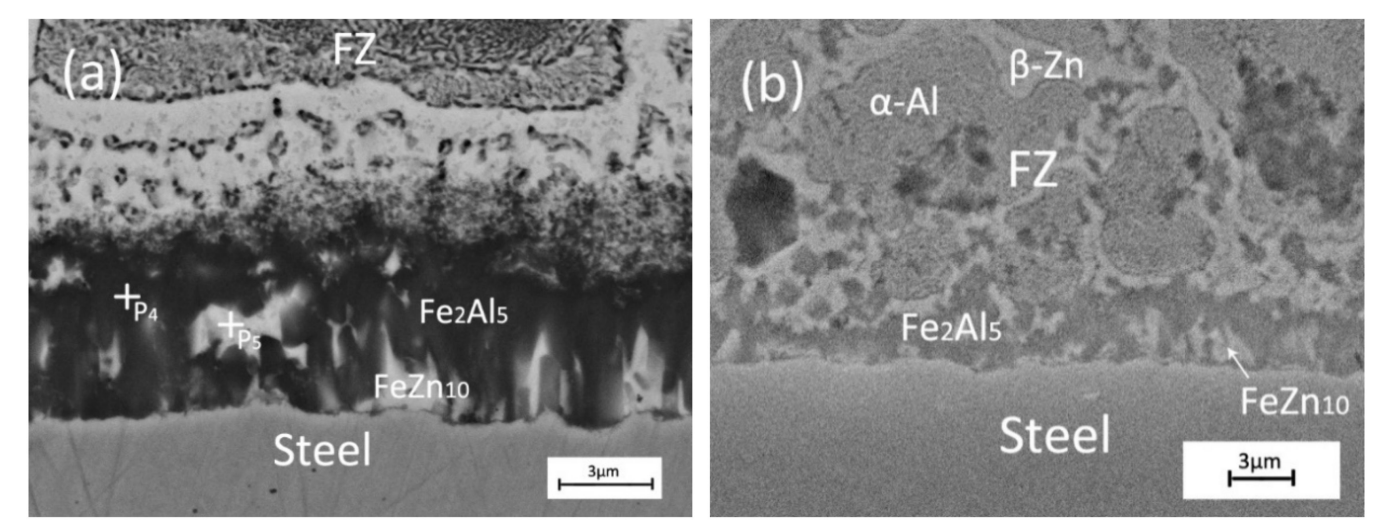

Figure 5. BEI images of laser Al/bare steel joint at different zones: (a) direct irradiation zone; (b) FZ root. 
Table 5. Energy-dispersive X-ray spectrometer (EDS) analysis of the marked points in Figures 4 and 5 in at.\%.

\begin{tabular}{cccccc}
\hline Point & Al & Fe & Zn & Ni & Possible Phases \\
\hline P1 & $6.1 \pm 0.7$ & - & $74.4 \pm 0.3$ & $19.4 \pm 0.5$ & $\mathrm{Ni}_{5} \mathrm{Zn}_{21}$ \\
P2 & $68.9 \pm 0.9$ & - & $3.5 \pm 0.3$ & $27.6 \pm 0.4$ & $\mathrm{Al}_{3} \mathrm{Ni}$ \\
P3 & $69.5 \pm 5.1$ & - & $7.2 \pm 0.9$ & $23.2 \pm 4.5$ & $\mathrm{Al}_{3} \mathrm{Ni}$ \\
P4 & $71.6 \pm 0.5$ & $23.8 \pm 0.1$ & $4.6 \pm 0.5$ & - & $\mathrm{Fe}_{2} \mathrm{Al}_{5}$ \\
P5 & $10.8 \pm 3.6$ & $9.7 \pm 1.8$ & $79.5 \pm 3.1$ & - & $\mathrm{FeZn}_{10}$ \\
\hline
\end{tabular}

Figure 5 shows the BEI of the interfacial region in the $\mathrm{Al} /$ bare steel joint. In the direct irradiation zone, two phases were seen in an 8- $\mu \mathrm{m}$ thick reaction layer. Based on EDS analysis, the average chemical composition of the dark matrix was $71.6 \pm 0.5$ at. $\% \mathrm{Al}, 23.8 \pm 0.1$ at. $\% \mathrm{Fe}$, and $4.6 \pm 0.5$ at. $\% \mathrm{Zn}$, while the light granular phase had an average composition of $10.8 \pm 3.6$ at. $\% \mathrm{Al}$, $9.7 \pm 1.8$ at.\% $\mathrm{Fe}$, and $79.5 \pm 3.1$ at. $\% \mathrm{Zn}$. According to the $\mathrm{Al}-\mathrm{Fe}-\mathrm{Zn}$ phase diagram and related studies [23], the possible phases were $\mathrm{Fe}_{2} \mathrm{Al}_{5}$ and $\mathrm{FeZn}_{10}$ (Table 5). In the FZ root, the same phase components, i.e., $\mathrm{Fe}_{2} \mathrm{Al}_{5}$ and $\mathrm{FeZn}_{10}$, were formed at the reaction layer; however, the layer thickness decreased to around $4 \mu \mathrm{m}$. It suggested that the temperature variation along the interface of the laser $\mathrm{Al} /$ steel joint would not lead to the change in phase component, but rather only decrease the thickness of the interfacial layer. Thus, a homogeneous reaction layer was formed in the $\mathrm{Al} /$ bare steel joint.

\subsection{Mechanical Properties}

Figure 6 shows the microhardness profile of the interfacial region in the $\mathrm{Al} / \mathrm{Ni}$-coated steel joint and $\mathrm{Al} /$ bare steel joint. At least three measurements were conducted to obtain relatively accurate hardness results. For the $\mathrm{Al} / \mathrm{Ni}$-coated steel joint, the average microhardness of the interfacial layer at the direct irradiation zone was $318 \mathrm{HV}$, which was harder than FZ $(\sim 120 \mathrm{HV})$ and the Ni coating ( $255 \mathrm{HV})$. With regard to the FZ root, the average microhardness of the interfacial layer was $278 \mathrm{HV}$. For the $\mathrm{Al} /$ bare steel joint, a similar microhardness of the interfacial layer was obtained at the direct irradiation zone and the FZ root, which ranged from 512 to $526 \mathrm{HV}$. It was apparently much harder than that of the $\mathrm{Al} / \mathrm{Ni}$-coated steel joint. It was reported that $\mathrm{Fe}_{2} \mathrm{Al}_{5}$ was the hardest phase among all of the Fe-Al IMCs, which was responsible for the higher microhardness in the $\mathrm{Al} /$ bare steel joint. Besides, it was well established that a higher microhardness indicated a more brittle microstructure [8,9]. That was to say, the interfacial reaction layer with the $\mathrm{Al} / \mathrm{Ni}$-coated steel joint could be much less brittle than that of the $\mathrm{Al} /$ bare steel joint.

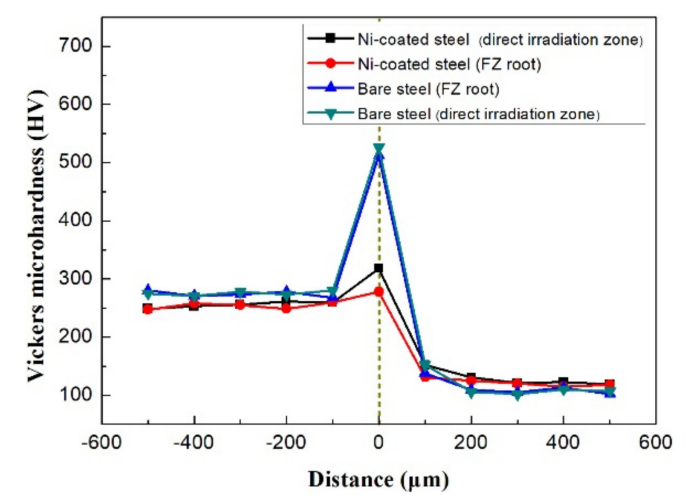

Figure 6. Hardness distribution across the interface of the $\mathrm{Al} /$ bare steel joint and $\mathrm{Al} / \mathrm{Ni}$-coated steel joint.

Tensile-shear testing results showed that the fracture load of the laser $\mathrm{Al} / \mathrm{Ni}$-coated steel joint reached $932 \pm 92 \mathrm{~N}$, while the fracture load of the laser Al/bare steel joint was only $743 \pm 65 \mathrm{~N}$. 
It was concluded that the joint fracture load increased by about $26 \%$ after inserting the Ni coating. The improvement on the fracture load will be discussed later.

\subsection{Fractography}

All of the tensile specimens were fractured at the $\mathrm{FZ} / \mathrm{Ni}$ coating interface in $\mathrm{Al} / \mathrm{Ni}$-coated steel joints. Figure 7 shows the SEM images and XRD pattern of the fracture surfaces for the laser $\mathrm{Al} / \mathrm{Ni}$-coated steel joint at different zones. Various fracture surface morphologies were observed at the direct irradiation zone. On the FZ side (Figure 7a), some tearing ridges were clearly observed that had the average chemical composition of $2.9 \pm 0.4$ at. $\% \mathrm{Al}, 74.0 \pm 2.7$ at. $\% \mathrm{Zn}$, and $23.1 \pm 3.0$ at. $\% \mathrm{Ni}$ (Table 6). It was confirmed as $\mathrm{Ni}_{5} \mathrm{Zn}_{21}$. Whereas, on the steel side (Figure $7 \mathrm{~b}$ ), fracture morphologies with different characteristics were observed, including a very smooth feature and some scattering rugged features on the top. The average chemical composition of $100 \mathrm{at} . \% \mathrm{Ni}$ was found at the smooth feature, while the scattering rugged feature contained $4.3 \pm 0.5$ at. $\% \mathrm{Al}, 72.2 \pm 1.8$ at. $\% \mathrm{Zn}$, and $21.9 \pm 1.6$ at.\% $\mathrm{Ni}$ (Table 6). Thus, it suggested that a mixed fracture consisting of shear brittle fracture at the $\mathrm{Ni}_{5} \mathrm{Zn}_{21} / \mathrm{Ni}$ interface and cleavage brittle fracture in the $\mathrm{Ni}_{5} \mathrm{Zn}_{21}$ layer occurred. At the FZ root, the characteristics of intergranular debonding were evident (Figure 7c,d). Based on EDS analysis, the FZ side and steel side had the respective chemical composition of $64.5 \pm 2.5$ at.\% Al, $8.5 \pm 3.3$ at. $\% \mathrm{Zn}, 27.0 \pm 1.3$ at. $\% \mathrm{Ni}$, and $66.1 \pm 2.3$ at. $\% \mathrm{Al}, 10.0 \pm 3.1$ at. $\% \mathrm{Zn}$, and $23.9 \pm 2.2$ at. $\% \mathrm{Ni}$ (Table 6). Hence, they could be identified as $\mathrm{Al}_{3} \mathrm{Ni}$. Thus, it inferred that the intergranular debonding occurred in $\mathrm{Al}_{3} \mathrm{Ni}$ layer. Figure 7e shows the $\mathrm{XRD}$ patterns of the fracture surface. Diffraction peaks of $\mathrm{Ni}_{5} \mathrm{Zn}_{21}$ and $\mathrm{Al}_{3} \mathrm{Ni}$ were detected on the $\mathrm{FZ}$ side, which confirmed the SEM and EDS results.
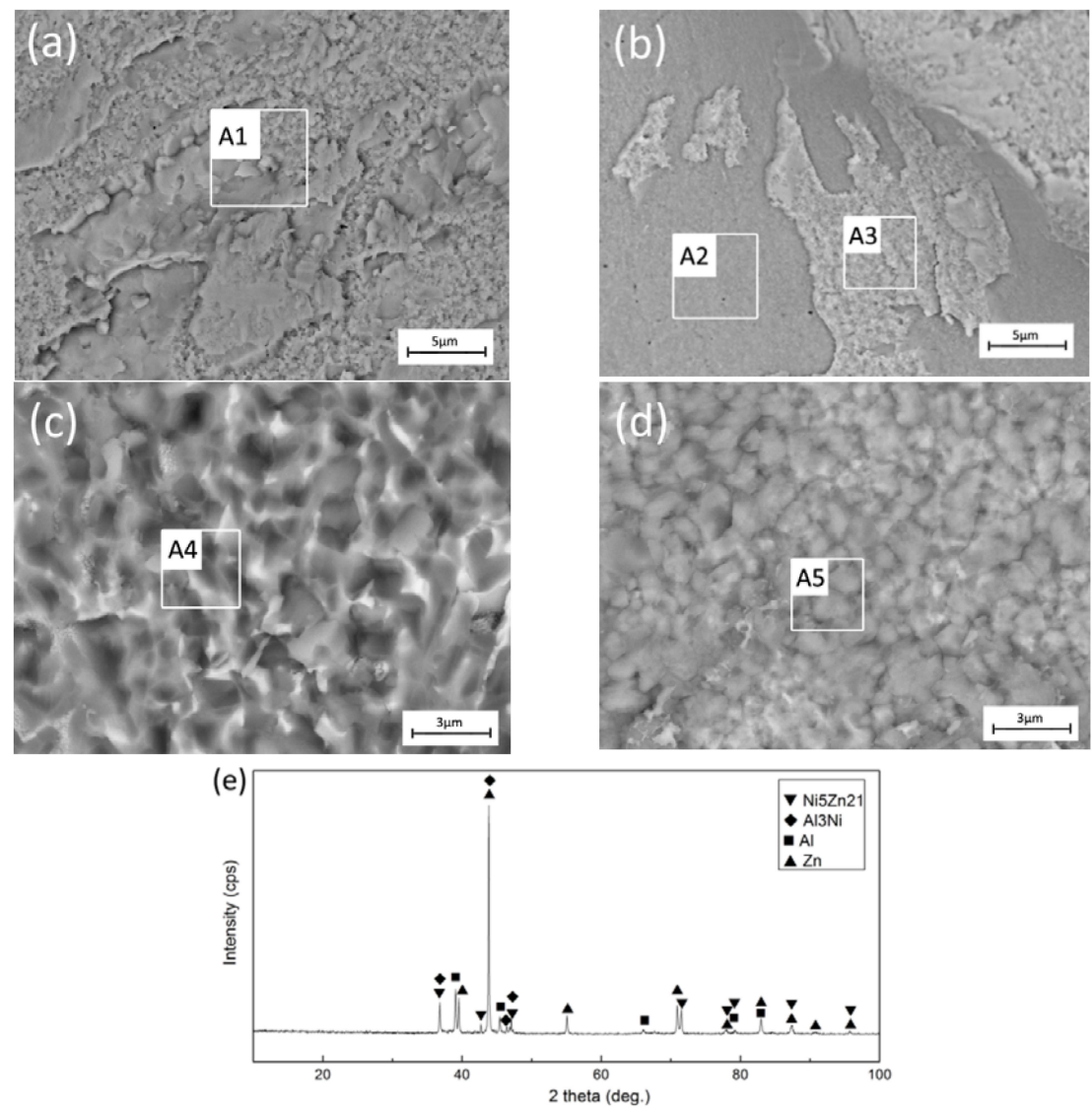

Figure 7. Fracture surface morphology and X-ray diffraction (XRD) pattern of the Al/Ni-coated steel joint: (a) FZ side at the direct irradiation zone; (b) steel side at the direct irradiation zone; (c) FZ side at the FZ root; (d) steel side at the FZ root and (e) XRD pattern at the FZ side. 
Table 6. EDS analysis of the marked areas in Figure 7 in at.\%.

\begin{tabular}{ccccc}
\hline Area & $\mathbf{A 1}$ & $\mathbf{Z n}$ & $\mathbf{N i}$ & Possible Phases \\
\hline A1 & $2.9 \pm 0.4$ & $74.0 \pm 2.7$ & $23.1 \pm 3.0$ & $\mathrm{Ni}_{5} \mathrm{Zn}_{21}$ \\
A2 & - & - & 100.0 & $\mathrm{Ni}$ \\
A3 & $4.3 \pm 0.5$ & $72.2 \pm 1.8$ & $21.9 \pm 1.6$ & $\mathrm{Ni}_{5} \mathrm{Zn}_{21}$ \\
A4 & $64.5 \pm 2.5$ & $8.5 \pm 3.3$ & $27.0 \pm 1.3$ & $\mathrm{Al}_{3} \mathrm{Ni}$ \\
A5 & $66.1 \pm 2.3$ & $10.0 \pm 3.1$ & $23.9 \pm 2.2$ & $\mathrm{Al}_{3} \mathrm{Ni}$ \\
\hline
\end{tabular}

In terms of the laser $\mathrm{Al} /$ bare steel joint, tearing ridges embedded with some light particles were evident in Figure 8a,b. Similar chemical composition was found at both fracture surfaces, which was $53.1 \pm 2.8$ at. $\% \mathrm{Al}, 31.9 \pm 3.1$ at.\% Fe, and $15.0 \pm 1.3$ at.\% $\mathrm{Zn}$. They were identified as $\mathrm{Fe}_{2} \mathrm{Al}_{5}$ and $\mathrm{FeZn}_{10}$. It suggested that the failure could occur at this reaction layer (Figure 5). Figure $8 \mathrm{c}$ shows the XRD patterns of the fracture surface. Diffraction peaks of $\mathrm{Fe}_{2} \mathrm{Al}_{5}$ and $\mathrm{FeZn}_{10}$ were obviously observed, corresponding to the SEM and EDS analysis. Besides, peaks of $\mathrm{FeZn}_{10}$ were mainly low diffraction peaks, suggesting that these IMCs in the form of particles existed adjacent to the interface.
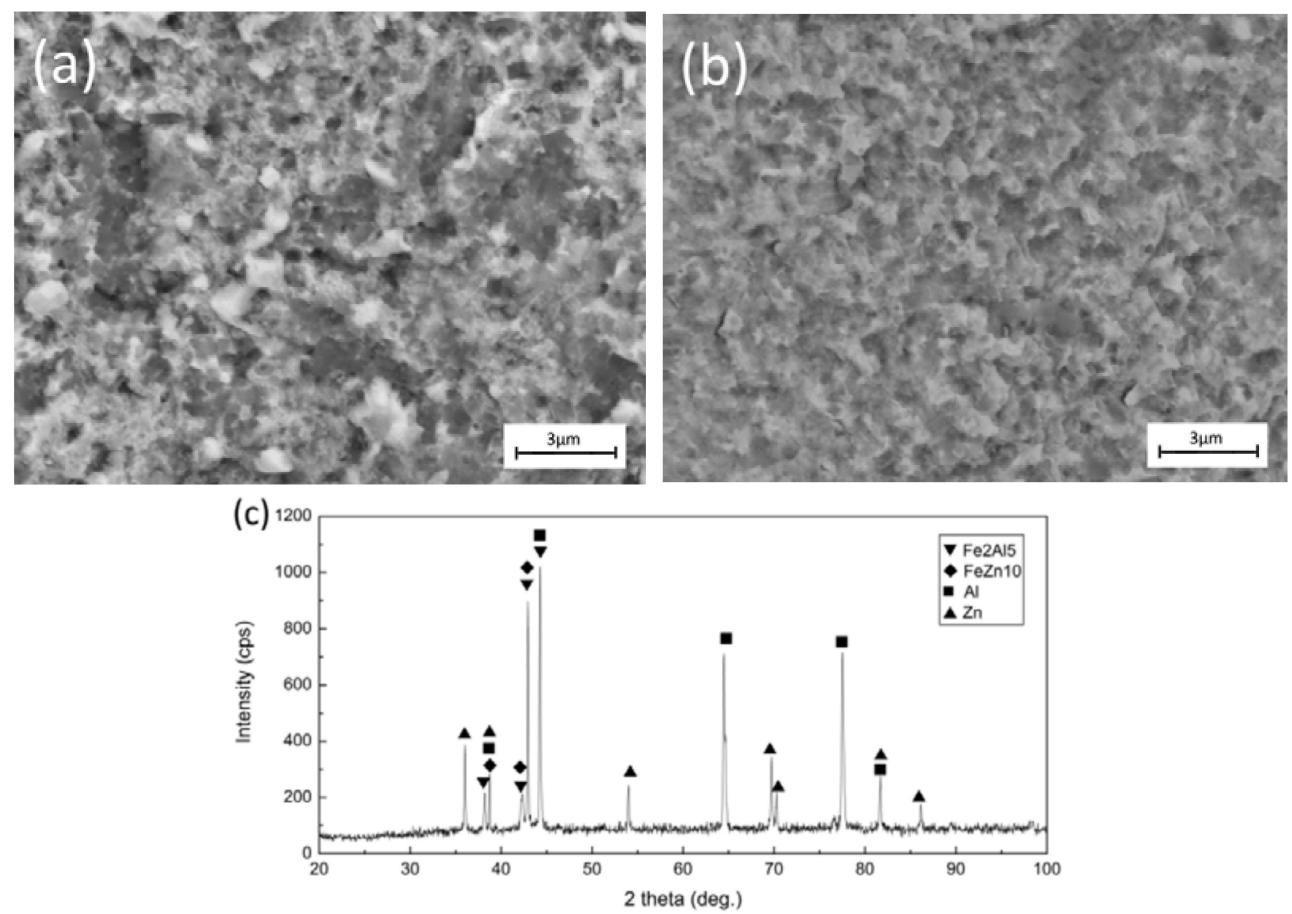

Figure 8. Fracture surface morphology and XRD patterns of the laser $\mathrm{Al} /$ bare steel joint: (a) FZ side; (b) steel side; and (c) XRD pattern at the FZ side.

\section{Discussion}

The above results of the microstructure and mechanical properties analysis indicated that the presence of $\mathrm{Ni}$ coating leads to the change of interfacial reaction products from $\mathrm{Fe}_{2} \mathrm{Al}_{5}$ and $\mathrm{FeZn}_{10}$ to $\mathrm{Ni}_{5} \mathrm{Zn}_{21}$ and $\mathrm{Al}_{3} \mathrm{Ni}$, which resulted in the improvement of joint mechanical properties. Thus, $\mathrm{Ni}$ coating has a significant effect on the joint strength enhancement, which will be discussed further below.

With the tailored energy distribution, the complete melting of $\mathrm{Ni}$ coating was avoided. Thus, the element mixing between $\mathrm{Al}$ and $\mathrm{Fe}$ could be thoroughly prohibited as the present of this physical barrier. Consequently, the formation of brittle $\mathrm{Fe}_{2} \mathrm{Al}_{5}$ was deterred. Instead, less brittle $\mathrm{Ni}_{5} \mathrm{Zn}_{21}$ and $\mathrm{Al}_{3} \mathrm{Ni}$ were formed at the interface. Less brittle reaction products had higher resistance to crack initiation and propagation during tensile loading. Thus, the joint strength was improved. 
Based on the analyses above, the joining mechanism of Al to Ni-coated steel was clarified with the aid of the schematic shown in Figure 9.

(a)

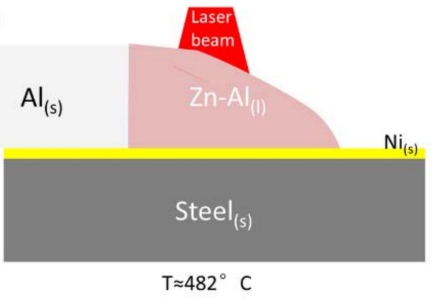

(b)

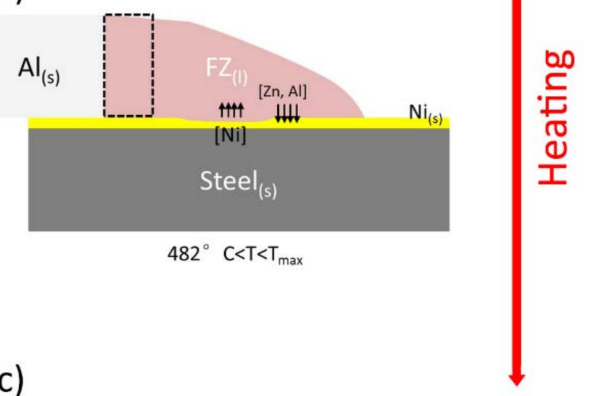

(c)

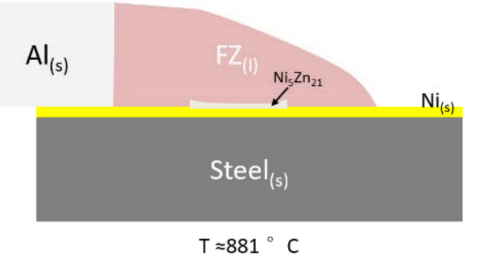

(d)

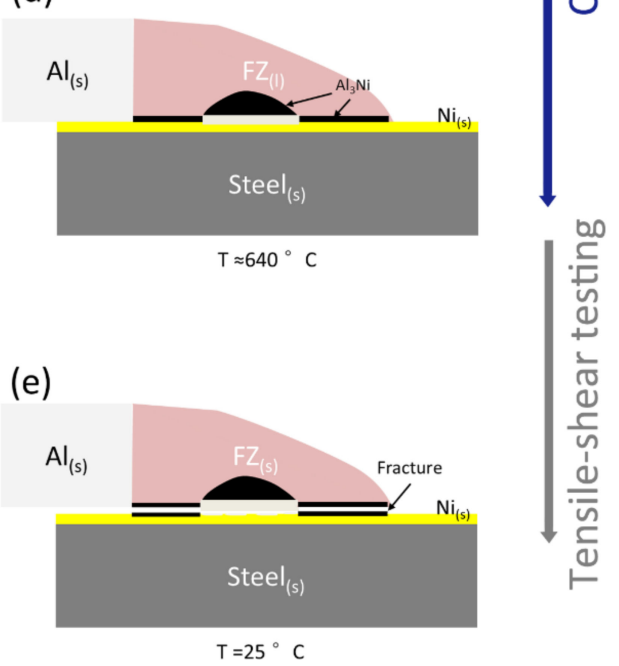

Figure 9. Schematic of joining mechanism: (a) melting of filler metal and its spreading on $\mathrm{Ni}$ coating; (b) partial melting of the $\mathrm{Al}$ base metal, excessive dissolution of $\mathrm{Ni}$, and element mutual diffusion; (c) formation of $\mathrm{Ni}_{5} \mathrm{Zn}_{21}$ at the direct irradiation zone; (d) formation of layered and dispersed $\mathrm{Al}_{3} \mathrm{Ni}$ at different zones; and (e) fractured joint.

Firstly, with the application of laser irradiation, melting of the filler metal occurred upon heating to the melting point of the filler metal $\left(\sim 482{ }^{\circ} \mathrm{C}\right)$. Then, the liquid filler metal wetted the Ni substrate and intimately contacted each other (Figure $9 \mathrm{a}$ ). When the temperature approached the melting point 
of the $\mathrm{Al}$ base metal, parts of the $\mathrm{Al}$ base metal started to melt, and then mixed with molten filler metal, forming the FZ. As the Gaussian distribution of the laser beam, it would result in a non-uniform thermal distribution at this region. It in turn led to various metallurgical reaction products at the interface. At the direct irradiation zone, the temperature would be higher, which resulted in the excessive dissolution of $\mathrm{Ni}$ and intense elemental diffusion (Figure 9b). Consequently, the $\mathrm{L}+\mathrm{Ni} \rightarrow \mathrm{Ni}_{5} \mathrm{Zn}_{21}$ transformation happened at $881{ }^{\circ} \mathrm{C}$ [24] (Figure 9c). While, at the FZ root, the lower temperature along with the limited dissolution of $\mathrm{Ni}$ and elemental diffusion was obtained, which only allowed the formation of $\mathrm{Al}_{3} \mathrm{Ni}$ through the transformation of $\mathrm{L}+\mathrm{Ni} \rightarrow \mathrm{Al}_{3} \mathrm{Ni}$ at $640{ }^{\circ} \mathrm{C}$ [25] (Figure 9d). A similar phase transformation occurred adjacent to $\mathrm{Ni}_{5} \mathrm{Zn}_{21}$ at the direct irradiation zone by a metallurgical reaction between dissolved $\mathrm{Ni}$ and FZ metal.

\section{Conclusions}

Laser welding/brazing of $\mathrm{Al}$ alloy to Ni-coated steel by characterization of a microstructure, hardness distribution, and joint fracture load was performed. The influence of $\mathrm{Ni}$ coating was clarified by comparing the $\mathrm{Al} /$ bare steel joints. The following conclusions were made:

(1) For the $\mathrm{Al} / \mathrm{Ni}$-coated steel joint, a nonhomogeneous reaction layer was observed at the interface: $\mathrm{Ni}_{5} \mathrm{Zn}_{21}$ formed at the direct irradiation zone, while $\mathrm{Al}_{3} \mathrm{Ni}$ formed at the $\mathrm{FZ}$ root.

(2) For the $\mathrm{Al} /$ bare steel joint, a homogeneous reaction layer consisting of $\mathrm{Fe}_{2} \mathrm{Al}_{5}$ and $\mathrm{FeZn}_{10}$ was formed at the interface.

(3) The microhardness of the interfacial reaction layer in an $\mathrm{Al} / \mathrm{Ni}$-coated steel joint is $278-318 \mathrm{HV}$, which is much lower than that of the $\mathrm{Al} /$ bare steel joint ( 512-526 HV).

(4) The fracture load of the $\mathrm{Al} /$ bare steel joint was only $743 \pm 65 \mathrm{~N}$, but it improved to $932 \pm 92 \mathrm{~N}$ by adding the Ni coating.

(5) The Ni coating acted a physical barrier to avoid the direct mixing of elements $\mathrm{Fe}$ and $\mathrm{Al}$, which inhibited the formation of brittle $\mathrm{Fe}_{2} \mathrm{Al}_{5}$. Hence, it led to the improvement of joint strength.

Author Contributions: J.Y. conceived and performed the experiments, analyzed the data, and wrote the paper. N.Z., Z.Y. and Y.L. provided the experimental materials and laboratory equipment, and directed the research. Z.Z., W.Z., J.C. and P.Z. contributed to the discussion and interpretation of the results.

Acknowledgments: This work was supported by National Natural Science Foundation of China (grant Nos. 51665038, 51775091 and 51605276), Key Project of the Natural Science Foundation of Jiangxi Province (grant No. 20171ACB21011) and the Science and Technology Planning Project of Sichuan Province (grant No. 2018GZ0284).

Conflicts of Interest: The authors declare no conflicts of interest.

\section{References}

1. Guo, W.; Wan, Z.; Peng, P.; Jia, Q.; Zou, G.; Peng, Y. Microstructure and mechanical properties of fiber laser welded QP980 steel. J. Mater. Process. Technol. 2018, 256, 229-238. [CrossRef]

2. Xia, H.; Zhao, X.; Tan, C.; Chen, B.; Song, X.; Li, L. Effect of Si content on the interfacial reactions in laser welded-brazed Al/steel dissimilar butted joint. J. Mater. Process. Technol. 2018, 258, 9-21. [CrossRef]

3. Urbikain, G.; Perez, J.M.; López de Lacalle, L.N.; Andueza, A. Combination of friction drilling and form tapping processes on dissimilar materials for making nutless joints. Proc. Inst. Mech. Eng. Part B J. Eng. Manuf. 2018, 232, 1007-1020. [CrossRef]

4. Ding, Y.; Shen, Z.; Gerlich, A.P. Refill friction stir spot welding of dissimilar aluminum alloy and AlSi coated steel. J. Manuf. Process. 2017, 30, 353-360. [CrossRef]

5. Mirza, F.A.; Macwan, A.; Bhole, S.D.; Chen, D.L.; Chen, X.G. Effect of welding energy on microstructure and strength of ultrasonic spot welded dissimilar joints of aluminum to steel sheets. Mater. Sci. Eng. A 2016, 668, 73-85. [CrossRef]

6. Acarer, M.; Demir, B. An investigation of mechanical and metallurgical properties of explosive welded aluminum-dual phase steel. Mater. Lett. 2008, 62, 4158-4160. [CrossRef] 
7. Yang, J.; Li, Y.L.; Zhang, H. Microstructure and mechanical properties of pulsed laser welded $\mathrm{Al} /$ steel dissimilar joint. Trans. Nonferr. Met. Soc. China 2016, 26, 1002-1010. [CrossRef]

8. Cao, R.; Chang, J.H.; Huang, Q.; Zhang, X.B.; Yan, Y.J.; Chen, J.H. Behaviors and effects of Zn coating on welding-brazing process of Al-Steel and Mg-steel dissimilar metals. J. Manuf. Process. 2018, 31, 674-688. [CrossRef]

9. Chen, J.; Li, J.; Amirkhiz, B.S.; Liang, J.; Zhang, R. Formation of nanometer scale intermetallic phase at interface of aluminum-to-steel spot joint by welding-brazing process. Mater. Lett. 2014, 137, 120-123. [CrossRef]

10. Yang, J.; Yu, Z.; Li, Y.; Zhang, H.; Guo, W.; Zhou, N. Influence of alloy elements on microstructure and mechanical properties of $\mathrm{Al} /$ steel dissimilar joint by laser welding/brazing. Weld. World 2018, 62, 427-433. [CrossRef]

11. Wang, C.; Cui, L.; Mi, G.; Jiang, P.; Shao, X.; Rong, Y. The influence of heat input on microstructure and mechanical properties for dissimilar welding of galvanized steel to 6061 aluminum alloy in a zero-gap lap joint configuration. J. Alloys Compd. 2017, 726, 556-566. [CrossRef]

12. Qin, G.; Ji, Y.; Ma, H.; Ao, Z. Effect of modified flux on MIG arc brazing-fusion welding of aluminum alloy to steel butt joint. J. Mater. Process. Technol. 2017, 245, 115-121. [CrossRef]

13. Tan, C.; Lu, Q.; Chen, B.; Song, X.; Li, L.; Feng, J.; Wang, Y. Influence of laser power on microstructure and mechanical properties of laser welded-brazed Mg to Ni coated Ti alloys. Opt. Laser Technol. 2017, 89, $156-167$. [CrossRef]

14. Sun, M.; Niknejad, S.T.; Zhang, G.; Lee, M.K.; Wu, L.; Zhou, Y. Microstructure and mechanical properties of resistance spot welded AZ31/AA5754 using a nickel interlayer. Mater. Des. 2015, 87, 905-913. [CrossRef]

15. Yang, J.; Yu, Z.; Li, Y.; Zhang, H.; Zhou, N. Laser welding/brazing of 5182 aluminium alloy to ZEK100 magnesium alloy using a nickel interlayer. Sci. Technol. Weld. Join. 2018, 1-8. [CrossRef]

16. Oliveira, J.P.; Panton, B.; Zeng, Z.; Andrei, C.M.; Zhou, Y.; Miranda, R.M.; Fernandes, F.B. Laser joining of NiTi to Ti6Al4V using a niobium interlayer. Acta Mater. 2016, 105, 9-15. [CrossRef]

17. Chen, S.; Huang, J.; Ma, K.; Zhang, H.; Zhao, X. Influence of a Ni-foil interlayer on Fe/Al dissimilar joint by laser penetration welding. Mater. Lett. 2012, 79, 296-299. [CrossRef]

18. Chen, S.; Huang, J.; Ma, K.; Zhao, X.; Vivek, A. Microstructures and mechanical properties of laser penetration welding joint with/without Ni-foil in an overlap steel-on-aluminum configuration. Metall. Mater. Trans. A 2014, 45, 3064-3073. [CrossRef]

19. Yang, J.; Li, Y.; Zhang, H.; Guo, W.; Weckman, D.; Zhou, N. Dissimilar laser welding/brazing of 5754 aluminum alloy to DP 980 steel: Mechanical properties and interfacial microstructure. Metall. Mater. Trans. A 2015, 46, 5149-5157. [CrossRef]

20. Li, L.; Tan, C.; Chen, Y.; Guo, W.; Hu, X. Influence of Zn coating on interfacial reactions and mechanical properties during laser welding-brazing of Mg to steel. Metall. Mater. Trans. A 2012, 43, 4740-4754. [CrossRef]

21. Yang, J.; Li, Y.L.; Zhang, H.; Guo, W.; Zhou, Y. Control of interfacial intermetallic compounds in Fe-Al joining by Zn addition. Mater. Sci. Eng. A 2015, 645, 323-327. [CrossRef]

22. Peng, H.; Xu, S.; Wang, J.; Wu, C.; Tu, H.; Su, X. The $600{ }^{\circ} \mathrm{C}$ Isothermal Section of the Al-Ni-Zn Ternary System. J. Phase Equilib. Diffus. 2017, 38, 151-159. [CrossRef]

23. Raghavan, V. Al-Fe-Zn (Aluminum-Iron-Zinc). J. Phase Equilib. Diffus. 2013, 34, 32-34. [CrossRef]

24. Okamoto, H. Ni-Zn (nickel-zinc). J. Phase Equilib. 2003, 24, 280-281. [CrossRef]

25. Okamoto, H. Al-Ni (aluminum-nickel). J. Phase Equilib. Diffus. 2004, 25, 394. [CrossRef]

(C) 2018 by the authors. Licensee MDPI, Basel, Switzerland. This article is an open access article distributed under the terms and conditions of the Creative Commons Attribution (CC BY) license (http://creativecommons.org/licenses/by/4.0/). 